\title{
Endoscopic ampullectomy: to inject or not to inject? The underwater technique
}

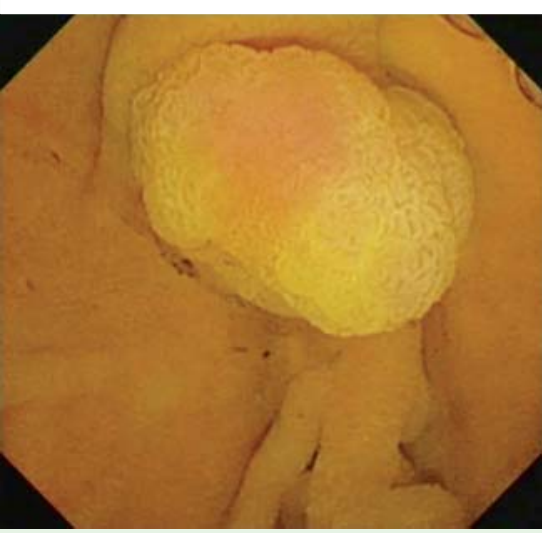

Fig. 1 Abnormal major papilla (underwater view).

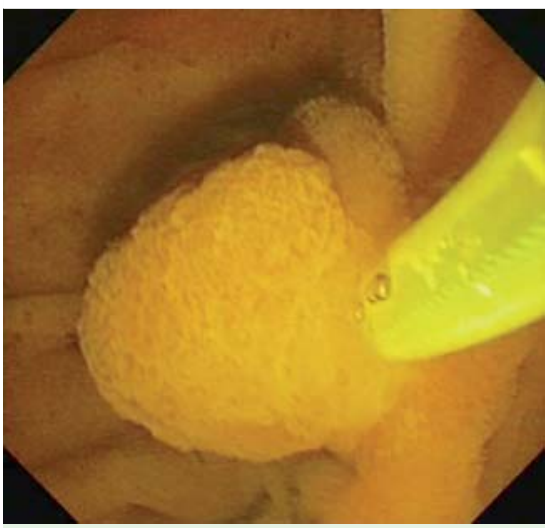

Fig. 2 Ensnared papilla during underwater ampullectomy.

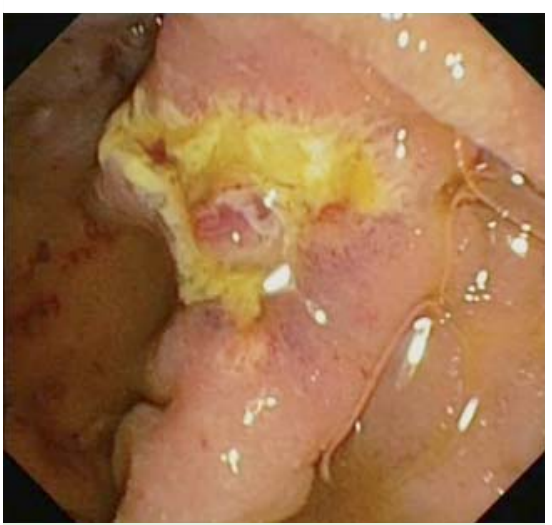

Fig. 3 Endoscopic view following underwater ampullectomy.
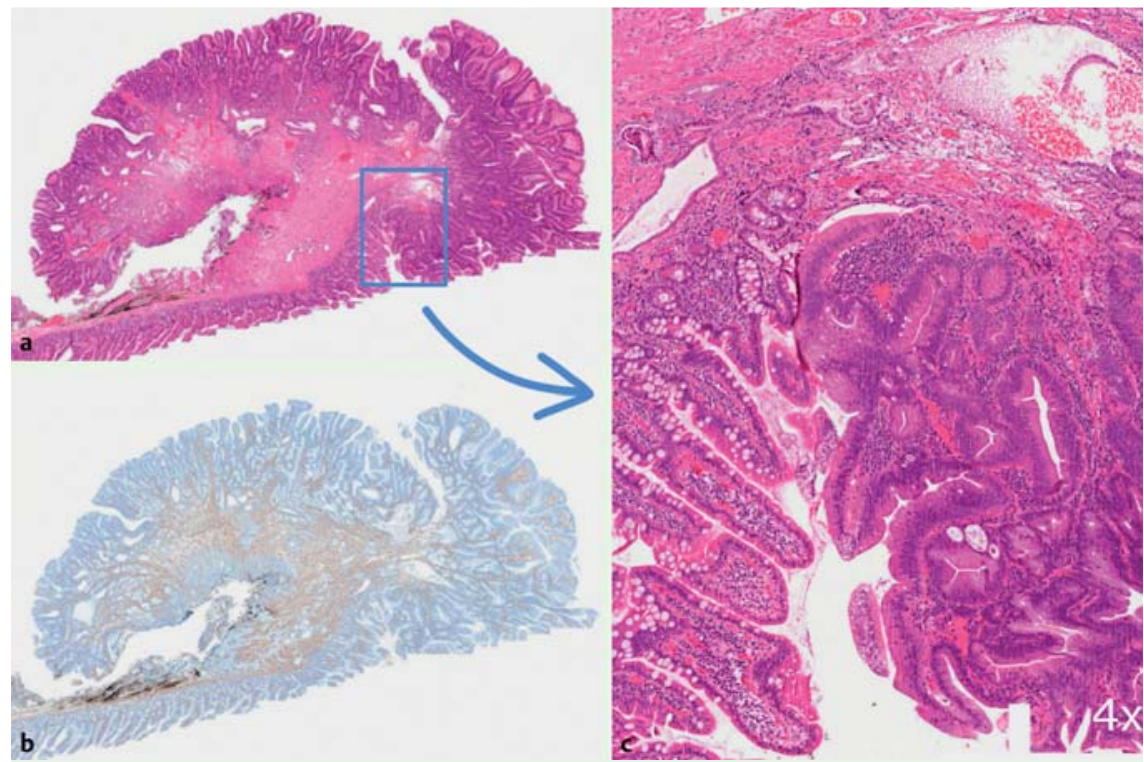

Fig. 4 Histological pictures. a Hematoxylin and eosin (H\&E) low-power magnification microphotography showing the entire thickness of the resection (black ink on the deeper margin). b Smooth muscle actin stain confirms the muscularis mucosa layer. c Normal colonic mucosa on the right and dysplastic mucosa on the left (focal cribriform glandular architecture, high grade dysplasia) (H\&E×4).

A 70-year-old man with a history of abdominal pain underwent esophagogastroduodenoscopy, which showed an abnormal major papilla of about $2 \mathrm{~cm}$ in diameter with a villous surface ( $\boldsymbol{\bullet}$ Fig. $\mathbf{1})$. Histology revealed a tubulovillous adenoma with focal high grade dysplasia. On endoscopic ultrasound, the lesion was confined to the mucosal layer.

Inspired by the work of Binmoeller et al. on their new approach, termed "The Underwater Technique," for resection of nonampullary duodenal adenomas [1], we planned an endoscopic underwater ampullectomy.

The duodenoscope was equipped with an auxiliary water jet injection cap (BioShield irrigator; US Endoscopy, Mentor, Ohio, United States), to allow irrigation while leaving the operative channel free. Carbon dioxide insufflation was off during resection.

En bloc ampullectomy was performed with a standard polypectomy snare, using blended current (VIO 300D, DRY CUT, effect 5, 60 watts; ERBE Elektromedizin GmbH, Tübingen, Germany) ( $\mathbf{F i g .} 2$ and - Fig.3). The procedure was uneventful, and the patient was discharged 36 hours later.
Pathology confirmed the diagnosis of tubulovillous adenoma with high grade dysplasia. Resection margins were free of dysplasia, and the muscularis mucosae was entirely removed, as confirmed by smooth muscle actin immunohistochemical stain ( $\bullet$ Fig.4). At 3-month followup, endoscopy showed complete duodenal healing, with no histologic recurrence. Ampullary adenomas can occur sporadically or manifest as syndromes of genetic conditions, and can transform into malignant ampullary cancer [2]. Several authors advocate submucosal injection immediately before endoscopic ampullectomy, as done for resection of colorectal polyps. Others opt not to use submucosal injection. There are insufficient data to conclude that this is a necessary step in the procedure [2-5].

On the basis of Binmoeller's results, we applied the underwater technique for endoscopic ampullectomy. Although the efficacy of this technique cannot be fully demonstrated with a single report, this application appeared to be feasible and safe, and we believe it may represent a potential alternative endoscopic approach to resection of ampullary adenomas. 
Endoscopy_UCTN_Code_TTT_1AR_2AF

Competing interests: None

\section{Antonino Granata ${ }^{1, *}$, Gabriele Curcio $^{1, *}$, Dario Ligresti ${ }^{1}$, Luca Barresi ${ }^{1}$, Tarantino Ilaria ${ }^{1}$, Rosa Liotta ${ }^{2}$, Mario Traina ${ }^{1}$}

${ }^{1}$ Endoscopy Services, Department of Diagnostic and Therapeutic Services, Mediterranean Institute for Transplantation and Advanced Specialized Therapies (ISMETT), Palermo, Italy

2 Pathology Service, Department of Diagnostic and Therapeutic Services, Mediterranean Institute for Transplantation and Advanced Specialized Therapies (ISMETT), Palermo, Italy

* Both authors contributed equally to this work.

\section{References}

1 Binmoeller KF, Shah JN, Bhat YM et al. "Underwater" EMR of sporadic laterally spreading nonampullary duodenal adenomas (with video). Gastrointest Endosc 2013; 78: 496-502

2 Hirota WK, Zuckerman MJ, Adler DG et al. ASGE guideline: the role of endoscopy in the surveillance of premalignant conditions of the upper GI tract. Gastrointest Endosc 2006; 63: 570-580

3 Baille J. Endoscopic ampullectomy. Am J Gastroenterol 2005; 100: 2379-2381

4 Norton ID, Gostout CJ, Baron TH et al. Safety and outcome of endoscopic snare excision of the major duodenal papilla. Gastrointest Endosc 2002; 56: 239-243

5 Catalano MF, Linder JD, Chak A et al. Endoscopic management of adenoma of the major duodenal papilla. Gastrointest Endosc 2004; 59: 225-232

\section{Bibliography}

Dol http://dx.doi.org/

10.1055/s-0034-1377538

Endoscopy 2014; 46: E478-E479

(c) Georg Thieme Verlag KG

Stuttgart · New York

ISSN 0013-726X

\section{Corresponding author}

\section{Antonino Granata, MD}

Endoscopy Service

ISMETT/UPMC

Via Tricomi 5

90127 Palermo

Italy

Fax: +39-091-2192400 (specify Endoscopy Service)

agranata@ismett.edu 